\title{
Methodological proceedings to evaluate the physical accessibility in urban historic sites
}

\author{
Gabriela Sousa Ribeiro ${ }^{\mathrm{a},{ }^{*}}$, Laura Bezerra Martins ${ }^{\mathrm{a}}$ and Circe Maria Gama Monteiro ${ }^{\mathrm{b}}$ \\ ${ }^{a}$ Department of Design, Federal University of Pernambuco, Professor Moraes Rego Avenue, 1235 - Cidade \\ Universitária. Recife, Pernambuco, Brazil. \\ ${ }^{\mathrm{b}}$ Department of Architecture and Urbanism, Federal University of Pernambuco, Professor Moraes Rego Avenue, \\ 1235 - Cidade Universitária. Recife, Pernambuco, Brazil.
}

\begin{abstract}
Historic urban sites are set by cultural and social diversities, generating multiple activities and use and access to these sites should be available to all people including those with disabilities. Taking into consideration that using the same methodology that was used in different historic sites researches with positive results facilitates replication, we aimed to develop methodological procedures that identify conditions of physical accessibility in open public spaces and access to public buildings in historic urban sites to support proposals about design requirements for improvements to the problems diagnosed and control inadequacies of the physical environment. The study methods and techniques from different areas of knowledge culminated in a proposal built with an emphasis on user participation that could be applied with low cost and in relatively short period of time.
\end{abstract}

Keywords: urban historic sites, physical accessibility, methodological procedures, ergonomics of the built environment, public space

\section{Introduction}

There are cultural and social diversities in urban historic sites that generates multiple activities and it is necessary to provide access to these sites for all people, including those with disabilities.

The environment influences the way users perform a task [8]. In relation to people with disabilities, it is important to highlight that unfavorable access and integration can segregate these portions of the population even more, excluding them from society, preventing them from exercising the role of citizens as any other individual.

Based on documental and bibliographical research, we can state that society disregard the needs of people with disabilities and deny them full access to its historical urban sites. Also, there was a lack of methodology that enabled us to fully respond to the issues of physical accessibility in these locations. We argue that using the same approach would allow the comparison between different studies in different areas of historic preservation in order to find effective solutions.

In this way, our research question is: what methods and / or techniques could help designers, architects and ergonomists in their activities concerning historic urban sites?

From this main question, we sought to develop a methodological procedure to identify, with user's participation , the conditions of physical accessibility of public open spaces and access of buildings in historic urban sites, in order to support requirements about design issues to improve the diagnosis and control of the physical inadequacies.

We based our research on two premises: to fulfill its historic and cultural role, historic sites need to preserve its lives, allowing enjoyment for people [3], people need to understand the space as their own, identifying themselves with it in order to preserve it [24].

\footnotetext{
* E-mail: gabrielasousaribeiro@gmail.com.
} 
Full accessibility allows a greater number of people to get access to buildings, to learn its historical and cultural value, feel integrated in that culture and make them want to preserve assets that represent it.

Moreover, accessibility in historic sites is contained in the International Charter for the Conservation and Restoration of Monuments and Sites (The Venice Charter-1964) : "the removal of all or part of the monument should not be allowed, except when as required for the conservation of the monument or for reasons of major national or international interest "[16, emphasis added].

When considering the significant number of people with disabilities in the world, the increasing longevity of the world population and the proportion of functional problems, linked to the emergence of some kind of restriction and/or disability that increases naturally with age, allowing full use and access to a significant portion of the population should be regarded as a global concern, because of the importance of material gain and social and cultural rights that such access brings.

To achieve the objectives, literature and documentary searches were conducted in order to prepare The Methodological Procedures for Evaluation of Physical Accessibility in Urban Historic Sites.

This methodological approach was applied and evaluated in the historic city of Olinda, Pernambuco, Brazil, obtaining satisfactory results.

\section{Methodology}

Literature searches were conducted on topics related to universal design, accessibility, ergonomics, cultural tourism, heritage, methods and techniques from different areas of knowledge that consider user's participation indispensable to the achievement of goals. Bibliographic and documentary searches were done concerning environments that underwent historic-cultural interventions to improve accessibility and national and international laws that deal with the issue.

Data crossing was carried out to obtain a critical view of the subject and to define the interfaces between the concepts, methods and techniques researched and intended goals with the proposed methodological procedures.

\section{Synthesis of the methodological proposal}

The Proceedings for the Methodological Proposal was developed from the knowledge obtained in order to evaluate the physical conditions of accessibility in historic urban sites with the help of the people who go the locality. It was also developed to propose project requirements to improve the highlighted problems and thus aid the controlling actions to the inadequate physical environment.

The user's participation is imperative seeing as though they play an important role to the site. From such participation it is possible to draw out their necessities and expectations and act on it to create a higher propensity to preservation on these sites.

Also, it is important to assign a systemic and integrated character to the proposal, based on the intimate relationship between Human -Task - Environment.

The "Human" part of this relationship refers to the users of the local site in question. It is directed towards people with some kind of physical impairment, especially those physical and dimensional aspects the methodological proceedings focus on. It is assumed that the aspects mentioned are the most affected by the urban historic site displacement, changing its access routes. Therefore, the following can be admitted as users:

- Direct users: those which Interact directly with the place, performing tasks, living up the environment. They are classified into:

- frequent direct users: people who are in daily contact with the place. Residents and workers of the area being studied are included;

- sporadic direct users: people who visit the place once in a while. It reflects the people who visit the place for leisure/or tourism;

- Indirect users: those who aid the direct users with some physical impairment when moving and when making use of the historic place. Such aids can be given when helping push the wheelchair, when holding the person, when helping people with low mobility move around, when signaling barriers, etc.

The proposal aims to offer people with some kind of physical impairment the chance to take up as much of the place visited as anyone else. Thus, the "Task" to be conducted should enable these individuals to "move about in areas free from public circulation and have access to the urban equipments of a historic site (entry and way outs of buildings)”. 
The "Environment" refers to the whole area of study, that is, a certain urban historic site.

In order to consolidate the proposal, it was grounded on the concepts of Participative Ergonomics, Universal Design, Community Design [14] and PPS [26].

The studies about methods and techniques with an urban focus [25, 28, 23] highlighted the importance of indentifying the area in question. The proposal for data collection is reached through adaptations of the Social Representations Theory [18, 19] in conjunction with methods from behavior register in environments [8]. There is also interview tools elaborated from the literature review about guiding concepts and current legislation as well as observations and physical collection data. Design $[10,9,7,20]$ and psychology [22, 17] methods and techniques served as basis for the suggestions and solution stage of the proposal. It was then decided to organize the proposal in a simple manner, of easy execution and in a short period of time.

The proposal intends firstly to identify and systematize the studied environment; to bring out the user's awareness and then look for signs of constrains and potentials; confirm the defined problems and find solutions to correct them (figure 1).

Figure 1: graphic schematization of the four stages of the Methodological Proposal for the Evaluation of Physical Accessibility in Urban Historic Sites.
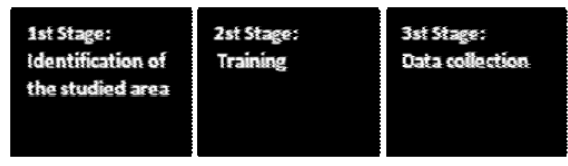

4st Stage: In search of project requirements

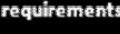

\subsection{1st Stage: Identification of the studied area}

Figure 2: graphic schematization of the Methodological Proposal for the Evaluation of Physical Accessibility in Urban Historic Sites, with emphasis on the first stage.

\begin{tabular}{|l|l|l|l|}
\hline $\begin{array}{l}\text { Ist Stage: } \\
\text { Identitication of } \\
\text { the studied area }\end{array}$ & $\begin{array}{l}\text { 2st Stage: } \\
\text { Trainine }\end{array}$ & $\begin{array}{l}\text { 3st Stage: } \\
\text { Datr collaction }\end{array}$ & $\begin{array}{l}\text { In seage: } \\
\text { project } \\
\text { requirements }\end{array}$ \\
\hline
\end{tabular}

It is proposed that identification and subdivision of the area to be studied be done due to the importance of acknowledging the studied area by the researchers [25] which provides subsidies to interpret the evaluation to be done by the users. This refers to the first stage from the methodological proceedings proposal (figure 2).
From the documental research, unsystematic observations and informal open interviews with frequent direct users, the following must be completed:

1 - identification of studied area, whose aims are to delimitate and describe the area in question. It must be illustrated with maps of the historic site, delimitating the research barriers in order to understand the systematization and particularities of the area studied.

2- identification of characteristics of the studied historic site. Historic characteristics must be collected (colonization, artistic style etc), predominant topography, dimension of tumbled and preserved areas to be worked on. The collection of these historic characteristics and of the dimension of the tumbled and preserved areas lead to the understanding of how the environment evolved over the years, your original and current functions as well as how they have undergone contemporary interventions. The dimensioning of the area to be worked on intends to quantify the research area.

3-identification of the kinds of activities led in delimitated study area. Activities related to tourism must be collected (types of tourism conducted, interrelationship between tourism and the most visited areas, visitor's characteristics); related to residential characteristics (areas with a greater residential concentration, residents 'characteristics); and the ones related to work and services (types of services given and the areas which stand out with the types of activities). Such proceedings justify themselves by the importance of getting to know the activities that take place in the study area in order to give solutions according with the necessities of the various types of users in each area, not to mention, indicate indirectly the environments that must be prioritized in the study.

In parallel to the identification of the studied area, the main ergonomic constraints must be listed in relation to the physical accessibility. To facilitate, in addition to documental research, unsystematic observations and informal interviews must follow the norms of NBR 9050/2004 [1], universal design principles and Ergonomic Problem Taxonomy [21]. The main barriers must be associated with the types of users that are most affected.

\subsection{2st Stage: Training}


Figure 3: Proposed graphic scheme of the Accessibility Evaluation Methodology for Physical Accessibility in historic urban sites. Emphasis on the 2st Stage.
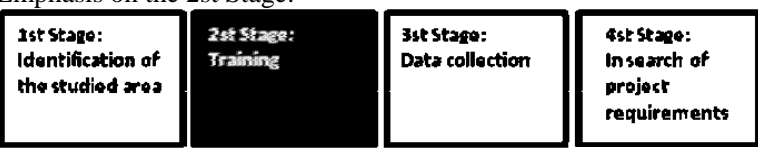

The active participation of users in all phases of the research generates a higher success rate in modifications [11].

The effective participation of users involves increasing levels of knowledge acquisition, changes in behavior and feedback controls, which should happen in a continuous and cumulative way [15]. Therefore, we emphasize the importance of conducting training with the users so that they are able to see problems and potentials of the study area on the 2 nd. Stage of the proposed methodology, as shown in Figure 3. For this, it is necessary to list a group of users who participate in all stages of the research. We propose that users are selected and set to form a "group representative", to be selected by a combination of cluster sampling with stratified sampling.

In the formation of population strata should be considered individuals who use different types of assistive technology, such as wheelchairs, crutches, walker, cane, prosthesis, among others.

To conduct the training, direct and indirect users should be selected depending on the size of the study area. They should be selected by taking into account the experience with the site being studying, and the availability and willingness of individuals to participate in the project. For research involving more than 20 people we suggest to divide the groups into two or more classes to facilitate and control the progress of the discussions.

For recruitment of people of any age, the motivation to attend the meetings should be enhanced by an incentive [22]. It is worth to provide transport facilities to get to the venue. In contrast, these incentives will have little effect when circumstances are beyond individual control, such as an illness. It is necessary to predict barriers to attendance when recruiting participants and to recruit a higher number than expected. We recommend a rate of around $20 \%$ above the calculated [22]. Researchers [6] suggest increasing this percentage with elderly and disabled participants and their carers.

The training should be conducted in a class participation form; the researcher must set out key points and hold constructive discussions with the participants. The main goal is to raise the awareness of their rights to come and go, and the significant economic participation of elderly people and people with disabilities in the market, including the tourist market. The discussion should make clear to participants that accessibility is not a matter of emotion, but of citizens' rights; that the market realizes the financial potential of this population.

The main issues to be addressed are: universal design, legislation, number of people with disabilities, economic potential of people with disabilities in the country and the world, tourism potential of this population, awareness of the importance user's voice in search of better accessibility conditions. It is important to point out some historic environments that were made accessible for people to realize that something is actually achievable. This training should serve also to explain to participants the objectives and stages of the research.

We believe that this awareness training will enable users to become "the voice of society" during much of the case study. When they become aware of their rights, of their importance in society, they will be able to conquer adequate space to fulfill their needs.

\subsection{3st Stage: Data collection}

Figure 4: Proposed graphic scheme of the Accessibility Evaluation Methodology for Physical Accessibility in Historic Urban Sites. Emphasis on the 3rd Stage.

\begin{tabular}{|c|c|c|c|}
\hline $\begin{array}{l}\text { 1st stage: } \\
\text { Identification of } \\
\text { the studied area }\end{array}$ & $\begin{array}{l}\text { 2st Stage: } \\
\text { Training }\end{array}$ & $\begin{array}{l}\text { 3st Stage: } \\
\text { Data collection }\end{array}$ & $\begin{array}{l}\text { 4st Stage: } \\
\text { Insearch of } \\
\text { projert } \\
\text { requirements }\end{array}$ \\
\hline
\end{tabular}

As highlighted in Figure 4, starts the 3rd. Stage data collection. We propose to use closed semistructured interviews with direct and indirect users of the site studied. At this stage, should be interviewed both people who were part of the training, the "group representative", the users present on the site studied at the time of interview, randomly selected, prioritizing those with physical restraint.

Based on the ergonomic constraints listed during the first stage of the study, in the NBR 9050/2004 [1], international standards of accessibility and universal design principles, closed interview should be used, where the user must assign to the items questioned the character of 'essential ',' recommended 'or' unnecessary '[2] for the proper functioning of the accessibility of the study site . Respondents may add additional items, not asked, but which they may consider relevant and should give them the same classification. 
The term 'indispensable' must be related to issues that users deem essential, totally necessary for people with disabilities to access and move around the study site. It means what "you cannot dismiss, which is absolutely necessary, essential, indispensable" [13].

The term 'recommended' should be given to issues that users consider important, but if they are not on the scene, it would still be possible to disable people move around and access the site. It is something "worthy of being recommended, desirable" [13].

The term 'dispensable' should be assigned to what users deem unnecessary, that does not make life easier for disabled people on site. "That may be waived" [13].

The results should be recorded on structured forms. The data obtained from the closed questions should be analyzed statistically. The suggestions from the users are ranked by similarity of meaning [5], and then tabulated statistically.

This stage is intended to demonstrate users' perception of those aspects necessary to increase the physical accessibility, to discuss the issues raised, and, indirectly, to obtain suggestions for improvement.

After the tabulations, the preparation for the "Enriched Accompanied walk" [8] was followed. The "Accompanied Walk" method [8] is done with guest visitors that is usually someone with some kind of impairment or has any relevant characteristic to the research. Courses and activities are proposed in advance and monitored to evaluate actions, behavior and relationship with the local user that we intend to evaluate. Field notebooks, tape records and videos are used to collect data. The researcher accompanies but does not help the subject.

The initial proposal for this stage of data collection was for the subject to move around reporting any difficulties and facilities found in the way (as suggested by the traditional model); the researcher would record on a map of the area the sections that presented major constraints with regard to physical accessibility. After completing the course, the subject would be interviewed in accordance to the Collective Subject Discourse (CSD) $[18,19]$.

In contrast, the application of this methodological proposal during field research in the historic site of Olinda, Pernambuco, Brazil [27] showed that the markings on the maps of the sections that impose major constraints is a redundant practice, since such information is easily obtained from the account of the subject along the path. It is recommended then to take this map out of the procedures for data collection which will help the researcher to assist the sub- ject over difficult sections to overcome potential barriers. The original method does not allow the researcher to assist the participant, however the practice has shown that when it comes to paths, historic sites, where the pavement is often very uneven and bumpy, the participant cannot overcome the barriers alone and being stopped by a barrier that he/she cannot overtake, the participant will not finalize the proposed route, making the research impossible. It is also suggested that a second research should follow the route in order to capture more accurate and complete data.

The tour above must be performed by users of the "representative group" because it is assumed that they already have enough knowledge to face the environment in the study as evaluators.

The routes for the "Enriched walks" should be defined a priori. It is suggested that the trial for such selection should occur during the first stage of the proposed methodological procedures, the identification of the study area stage.

It is proposed to be set at least three routes. This number can vary depending on the size of the area being studied. These should be selected considering how the participants make use of them: one is to be widely used by frequent direct users, other by sporadic direct users and a third by both. It is also important to select them by the degree of difficulty, choosing routes with low, medium and high level of difficulties in relation to physical accessibility.

At the end of the "Enriched Walk", a structured open interview based on the Collective Subject Discourse (CSD) should be applied. Drafted prior to the tour it must be conducted emphasizing the data obtained in first stage of the research (identification of the study area) and based on the guiding principles of ISO 9050/2004 [1], international standards of accessibility, PPS and Universal Design. Thus, one can investigate the users' views in relation to the views of other users and to the results obtained from the literature review.

The CSD [18, 19] attempts to describe and express a particular opinion or position on an issue in the present socio-cultural set. It is a research divided into some open questions to be answered by a sample population, each of these questions generates a varying number of different positions, i.e. different CSDs. Users must answer about the general conditions of physical accessibility of the historic city, the main barriers to people with physical impairments and risks derived from these, suggestions for improvements, beyond the issues raised by users in the first stage of data collection. 
It is assumed that this method provides important contributions to the capture of data on central ideas of different user groups, and the comparison of which are individual and collective thoughts.

It should be applied to frequent and infrequent users in order to see whether there is difference of opinion between these populations, as their experiences with the historic site study site are distinct. This method should be applied to the two groups: people who made the trip “Accompanied Enriched Walk” (the "group representative"), at the end of the tour, and people who did not take the tour, randomly selected in the study. Our intention is to capture data to inform if there is difference in perception by placing the subject on as an evaluator of the environmental conditions, particularly in relation to qualitative differences perceived by users.

Thus, indirectly, we evaluate the extent to which the accessibility or lack thereof, is striking in people's lives. And, in case of poor accessibility, it is understandable if people are already accustomed to this situation and see no more problems or if the condition is so critical that, although not acting as environmental assessors, there is no way to abstract reality.

After finishing the "Enriched Walk" and application of DSC based on interviews with users who have not taken the tours, you should proceed to tabulate the data.

The data obtained during the proposed routes for the tours must be transcribed and analyzed according to similarity of answers. Statistical analysis should be performed to identify the main problems and their consequences as seen by users. These data should be analyze in order to structure a map containing the most critical points in relation to the risks and discomforts and markings of the places that allow unattended movement and secure access according to the opinions of the participants. Through the Spectrum Accessibility Method [4], we can visualize the accessibility of the area studied, showing the more accessible routes to users with some physical impairments and to those that need intervention more urgently. The data obtained from interviews based on the DSC must be transcribed to carry out the analysis. Key Expressions, Central Ideas and Narrative Anchors must be extracted for the formation of collective subject's discourse.

Key Expressions are excerpts from verbal material of each statement that best describe its content. Central ideas are synthetic formulas that describe the meanings present in the material and also in sets of responses from different individuals, which has a similar meaning. Anchors are synthetic formulas that describe ideologies, values, beliefs, present in individual responses grouped in the form of general statements designed to fit particular situations. The method considers that anchors exist only in the verbal material, discursive explicit marks of general statements.

The CSDs are key expressions present in the reports, whose central ideas and / or anchors have similar of complementary sense. These key terms of similar meaning make collective statements written in first person singular, in order to mark the presence of collective thought in a person and in a collective discourse. It is as if everyone spoke like (or through) one [19].

\section{4. $4^{\text {th }}$ Stage: In search of project requirements}

Figure 5: graphic scheme of the Methodological Proposal for the Evaluation of Physical Accessibility in Urban Historic sites, with emphasis on the 4 th stage.

\begin{tabular}{|l|l|l|l|}
\hline $\begin{array}{l}\text { 1st Stage: } \\
\text { Identification of } \\
\text { the studied area }\end{array}$ & \begin{tabular}{ll|l} 
2st Stage: \\
Training
\end{tabular} & $\begin{array}{l}\text { 4st Stage: } \\
\text { Data collection }\end{array}$ & $\begin{array}{l}\text { in search of } \\
\text { project } \\
\text { requirements }\end{array}$ \\
\hline
\end{tabular}

The proposal finishes with the 4th stage (figure 5), which by strengthening the participative ergonomics precepts intermediates the constructive discussion between direct users and researchers about the aspects collected during the earlier stages in order to make recommendations about project requirements that may attend to all the population.

The main aim at this moment is the knowledge exchange. The local community is the one knows the area best, its peculiarities, thus offering the researchers a better comprehension about the way of living and thinking of the residents, their habits and forms of occupation and appropriation of space. On the other hand, the specialists have the technicalscientific capacities and facilities to administer to the environment [28]. Hence the importance of the collective discussion, so that a fair solution may be drawn for everyone. The formations of focus groups [22] are suggested in order to reach such results.

Proposals are elaborated to be submitted to the participants, who will be able to accept them, modify them or reject them. The result of this process must be an agreed product and owned up to by everyone [22].

The participants of this stage of the research must be those who compose the "representative group", since they have followed all the course of the re- 
search. Thus, they are the most prepared to make suggestions.

The proposal is that a group of 15 and 20 people be formed per session, aside from the moderator and your aiders. The group must be divided into small heterogeneous groups with 4 or 5 participants. Such division is justified so that there is greater interaction and mutual confidence between them, who are working "face to face" and improving the dynamic ad productivity of the task. In the case of studies with "group representatives" having over 20 people, it is suggested that it be divided into two or more groups for the session, depending on the number of participants.

With respect to the direct users, there is the possibility of this part of the population being composed of elderly people. These may present difficulties of attention holding, communication problems and interpretation, among other things [6].

For this reason, it is suggested that a solid "focus group" be made, which can be denominated of "Workshop".

A previous itinerary of questions (generated from the data obtained in the previous stages) must be made to be discussed and/or solved. In order to enrich the discussion e aid the maintenance of the participant's concentration, it is suggested that maps, photographs and/or videos be shown to illustrate the problems found and the localization of the same; boards for them to write on their main ideas; post its of various sizes, shapes and colors - these will allow that what has been written on it can be seen from a distance of 10 meters; they must also be placed on a panel with pins so that everyone may see them and reorder them when necessary. All these measures will enable a logical reasoning and group aim. Any other measures that can aid in controlling their attention, communication, memorization of discussed items and concatenation of ideas and thoughts are suggested.

The moderator is responsible for maintaining a good discussion environment; for organizing and guiding the discussion process without impairment or inhibiting the participation of those present so that the answers to the questions be formulated in conjunction and so that it be accepted by all [17].

The moderator will also conduct the group process and group production so that there is a trusting environment based on respect and purpose. All of this to facilitate interpersonal communication, to induce congruence of ideas, to stimulate their creativity and collaboration to get the task to the expected completion [12].
The collected group suggestions must be presented in other urban historic sites for the resolution of the prioritized problems. Amongst the prioritized problems and its solutions the group composed of users and researchers can decide on the most urgent, defining the short-term, medium and long-term interventions.

The sessions must be registered in audio and if possible in video as well, so that it can be easier to treat the data which will eventually define the requirements for the Project.

\section{Conclusion}

The design as a project discipline, allows products, processes and environments to be designed for people with disabilities to enjoy the environment on equal terms to others. The ergonomics as a scientific discipline that seeks to fit the spaces, processes and products to man, adds value as it puts the user in focus to improve their quality of life.

To support designers, architects and ergonomists in their activities relating to urban historic sites, it is necessary to use various methods and techniques from different areas of knowledge, among which stand out Participatory Ergonomics, Community Design, APO, DRUPA , Participatory Diagnosis of Conservation, CDS, walks, methods and techniques of design and Focus Group, and techniques of observations and interviews.

Through the study of all methods and techniques described above, it was noted and reaffirmed the importance of giving a voice to users, since the recognition of potential environmental problems suggested solutions to the negative aspects identified by using tools easily assimilated by disabled users , so that they can participate in the research to their satisfaction, without incurring constraints.

It is recognized that accessibility must be addressed holistically, with equal conditions to all, with or without disabilities, and those who have physical, visual, auditory and mental impairments. However, it was necessary to give an initial step, when investigating the task of displacement in the areas of free movement and public 'access' public buildings of a historic site, we focused on people with physical and motor impairments.

The proposed methodological procedures are not rigid and unchanging; on the contrary, they can be adapted to various situations. Through them it is possible to study historic sites in isolation. Moreover, 
they can be put into practice completely or in just some of your stages.

The proposed methodological procedures for evaluating physical accessibility in urban historic sites can help with the implementation of research conducted in the area so that it becomes easier to evaluate the possibility of reproducing to different locations the improvements reached in one. There will also be a database able to guide the improvement in the accessibility conditions in these areas. Thus, all this will allow that areas with historic-cultural meaning can be visited by everyone, whether they have a physical impairment or not.

\section{References}

[1] ABNT - Associação Brasileira de Normas Técnicas. NBR 9050: Acessibilidade a edificações, mobiliário, espaços e equipamentos urbanos. Rio de Janeiro, 2004.

[2] Aragall, F et al. Manual d'Accessibilitat per a les Platges del Litoral de la Província de Barcelona. Collecció Salut Pública. Platges, 2. Diputació Barcelona, 2003.

[3] Avrami, E et al. Values and Heritage Conservation. Los Angeles: The Getty Conservation Institute, 2000.

[4] Baptista AHN et al. O Método do Espectro de Acessibilidade. In: Encontro Nacional de Engenharia de Produção, 23, 2003, Ouro Preto-MG. Anais. ENEGEP 2003. Ouro Preto: ABEPRO, 2003.

[5] Bardini, L. Análise do Conteúdo. Lisboa: Edições 70, 2000.

[6] BarretA, J; Kirk, S. Running focus groups with elderly and disabled elderly participants. Applied Ergonomics, 31, 2000. p. 621-629.

[7] Baxter, M. Projeto de Produto - Guia prático para o design de novos produtos. 2. ed. São Paulo: Edgard Blücher, 2000.

[8] Bins Ely, VHM. Acessibilidade Espacial - condição necessária para o projeto de ambientes inclusivos. In Ergodesign do Ambiente Construído e Habitado: Ambiente urbano, Ambiente Público, Ambiente Laboral. Moraes, A. (org.). Rio de Janeiro: iUsEr, 2004.

[9] Bomfim, GA. Metodologia para desenvolvimento de projetos. João Pessoa: Editora Universitária UFPB, 1995. 69p.

[10] BONSIEPE, G. Teoría y práctica del deseño industrial. Barcelona: Gustavo Gilli, 1978.

[11] Brown Junior, O. The development and domain of participatory ergonomics. In: International Ergonomics Association World Conference / Brazilian Ergonomics Congress, 7, 1995, Rio de Janeiro. Proceedings... Rio de Janeiro: ABERGO, p.28-31.
[12] Colette, MM. Moderação. In: BROSE, M. (org.) Metodologia Participativa: uma introdução a 29 instrumentos. Porto Alegre: Tomo Editorial, 2001.

[13] Ferreira, ABH. Novo Aurélio Século XXI: o dicionário da língua portuguesa. 3. ed. rev. ampl. Rio de Janeiro: Nova Fronteira, 1999.

[14] Guy, B. Community Design Primer, 2002. On behalf of the environmental Leadership Program. Disponível em www.elpenet.org. Acesso em 05 de Janeiro de 2007, às 17h08min.

[15] Iida, I. Ergonomia: projeto e produção. 2. ed. rev. e ampl. São Paulo: Edgard Blücher, 2005.

[16] IPHAN - Instituto do Patrimônio Histórico e Artístico Nacional. Disponível em http://www.iphan.gov.br , acesso em 17 de abril de 2007, às 17h08min.

[17] Krueger, RA. Focus Groups a Practical Guide to Applied Research. Sage Publications, Thousand Oaks, 1994.

[18]Lefèvre, F; Lefèvre AMC. O discurso do sujeito coletivo: um novo enfoque em pesquisa qualitativa. Caxias do Sul: Educs; 2003.

[19] Lefèvre, F; Lefèvre AMC. O sujeito Coletivo que Fala. Interface - Comunic, Saúde,Educ, v.10, n.20, p.517-24, jul/dez 2006.

[20] Lobach, B. Design industrial: bases para a configuração de produtos industriais. São Paulo: Edgard Blücher, 2000.

[21] Moraes, A; Mont'Alvão, C. Ergonomia: conceitos e aplicações. 3ed. rev. e ampl. Rio de Janeiro: A de MORAES, 2003. 140p

[22] Morgan, DL. 'Focus groups as qualitative research' in Qualitative Research Methods Series,16. London: Sage Publications. 1997.

[23] Moura, MAS. Diagnóstico participativo de Unidades de Conservação - DiPUC. In: BROSE, M (org.) Metodologia participativa: uma introdução a 29 instrumentos. Porto Alegre: Tomo Editorial, 2001.

[24] Mouethé, C. Mobiliário Urbano. Rio de Janeiro: 2AB, 1998.

[25] Ornstein, SW et al. Ambiente Construído \& Comportamento: a Avaliação Pós-ocupação e a Qualidade Ambiental. São Paulo: Studio Nobel/FUPAM, 1995.

[26]PPS. Project For Public Spaces, INC., Place/ Community Driven Approach. In: www.pps.org. USA: Project for Public Spaces Inc, novembro, 2003. Acesso em 17 de dezembro de 2006, às $10 \mathrm{~h} 17 \mathrm{~min}$.

[27] Ribeiro, GS. Proposta de procedimentos metodológicos para avaliação da acessibilidade física em sítios históricos urbanos. Dissertação (Mestrado em Design). Universidade Federal de Pernambuco, Programa de Pós-Graduação em Design. Recife, 2008.

[28] Susin, J et al. Diagnóstico Rápido Urbano Participativo DRUP. In: BROSE, M (org.) Metodologia participativa: uma introdução a 29 instrumentos. - Porto Alegre: Tomo Editorial, 2001. 